\title{
EVALUACIÓN DE Toxoplasma gondii EN LLAMAS HEMBRAS DE DOS COMUNIDADES CAMPESINAS DE LA REGIÓN DE PUNO
}

\author{
Evaluation of Toxoplasma gondi in Female Llamas from Two Peasant \\ Communities in Puno
}
Eugenio Loayza M. ${ }^{1}$, Eva Casas A. ${ }^{1,2}$, Amanda Chávez V. ${ }^{1}$, Luis Coronado S. ${ }^{3}$, Cecilia Venturini De Arana ${ }^{4}$

\section{Resumen}

El objetivo del estudio fue determinar la presentación de Toxoplasma gondii en llamas hembras en edad reproductiva de dos comunidades campesinas de la provincia de Melgar, Puno. Se colectó muestras de sangre a 30 y 77 llamas de las comunidades de Huaycho y Huataywasi. Las muestras se procesaron con la técnica de inmunofluorescencia indirecta. La seroprevalencia hallada frente a T. gondii fue de $36.7 \%$ en Huaycho y $6.5 \%$ en Huataywasi. Ambas explotaciones presentaban condiciones y sistemas de manejo disímiles, por lo que el tipo de explotación, sistema de manejo y la presencia de hospedero definitivo influirían en la presentación de $T$. gondii en el ganado.

Palabras clave: Toxoplasma gondii, llamas, serología, anticuerpos, hospedero definitivo, sistema de manejo

\section{Abstract}

The objective the study was to determine the seroprevalence of Toxopasma gondii in adult female llamas from two peasant communities from the province of Melgar, Puno. Blood samples were collected in 30 and 77 llamas from Huaycho and Huataywasi communities. Samples were analyzed by the indirect immunofluorescent test. The seroprevalence to T. gondii was $36.7 \%$ in Huaycho and $6.5 \%$ in Huataywasi. Both communities showed different conditions and management systems, which can explain the high differences in seroprevalence.

Key words: Toxoplasma gondii, llama, serology, antibodies, definitive host, husbandry system

\footnotetext{
${ }^{1}$ Laboratorio de Microbiología y Parasitología Veterinaria ${ }^{3}$ Laboratorio de Zootecnia y Producción Agropecuaria, Facultad de Medicina Veterinaria, Universidad Nacional Mayor de San Marcos, Lima

${ }^{2}$ E-mail: evacasas99@gmail.com

${ }^{4}$ Laboratorio de Inmunoparasitología y Área de Inmunología Veterinaria, Dpto. de Epizootiología y Salud Pública,Facultad de Ciencias Veterinarias, Universidad Nacional de La Plata, Argentina
} 


\section{INTRODUCCIÓN}

La explotación de Camélidos Sudamericanos (CSA) es una de las principales actividades económicas de la población altoandina. Un vasto sector de la población depende de los CSA para satisfacer sus necesidades más elementales, dado que le sirve al criador como fuente de carne y fibra. Sin embargo, la producción de llamas y alpacas se encuentra con diversas limitantes, incluyendo problemas reproductivos (Ameghino y De Martini, 1991) de tipo infeccioso y parasitario, que afectan la eficiencia productiva del rebaño y la rentabilidad de los criadores (Franco et al., 1998).

Toxoplasma gondii es un protozoo perteneciente al Phylum Apicomplexa. Tiene como hospedero definitivo a los felinos (doméstico o silvestre) y como hospederos intermediarios a cerca de 200 especies (ovino, caprino, bovino, porcino, equino, felinos, aves y humanos, entre otros) (Luzón et al., 1997; Martín-Hernández y García-Izquierdo, 2003). Ocasiona problemas de tipo reproductivo, especialmente en el ovino y caprino, donde se encuentra asociado con abortos, fetos momificados y mortinatos, así como nacimiento de crías débiles. La enfermedad que produce es zoonótica, repercutiendo mayormente en la salud de niños y adultos con sistema inmunológico comprometido (MartínHernández y García-Izquierdo, 2003).

Su ciclo biológico comprende una fase sexual, la cual ocurre en las células epiteliales del intestino delgado de los felinos, con eliminación de ooquistes no esporulados al medio ambiente, que una vez esporulados se tornan infectivos; y de un ciclo asexual en los tejidos extraintestinales de hospederos intermediarios que ingieren los ooquistes esporulados.

Las técnicas utilizadas para el diagnóstico de $T$. gondii incluyen inmunohistoquímica del parásito en tejidos, la verificación de anticuerpos a través de la prueba de Sabin y Feldman, Hemaglutinación indirecta e Inmunofluorescencia indirecta, entre otras, y el uso del PCR como técnica biomolecular (Innes y Esteban-Redondo, 1997).

En Perú, la toxoplasmosis se ha reportado con prevalencias de $66 \%$ en ovinos del departamento de Junín (Caldas et al., 2006), y de 10 y $36 \%$ en llamas y alpacas de los departamentos de Puno y Cuzco (Saravia et al., 2004; Ramírez et al., 2005). La diseminación de $T$. gondii puede deberse a factores como presencia de hospederos definitivos, supervivencia de ooquistes en el medioambiente, sistema de manejo y crianza del ganado, por lo que se requiere realizar estudios que permitan conocer la real situación del parásito en los CSA del país; entre ellos, las llamas que se encuentran, casi en su totalidad, en manos de pequeños productores y comuneros (Fernández-Baca, 1991). Esto permitirá establecer medidas de control y de manejo adecuadas que aminoren su presentación. El presente estudio estuvo enfocado en determinar la presencia de llamas seropositivas a $T$. gondii en dos comunidades campesinas del departamento de Puno.

\section{Materiales y Métodos}

El estudio se realizó en el 2003 en dos explotaciones de llamas (Huaycho y Huataywasi) de los distritos de Nuñoa y Santa Rosa, provincia de Melgar, Puno. La zona tiene una altitud aproximada de $4000 \mathrm{msnm}$, temperaturas de -7 a $18{ }^{\circ} \mathrm{C}$, y precipitación pluvial anual de 600 a $800 \mathrm{~mm}$.

Se trabajó con 107 llamas hembras, en edad reproductiva ( 2 a 8 años), criadas a libre pastoreo y en contacto con diversas especies de animales domésticos y silvestres. Los animales se estratificaron considerando el lugar de procedencia (dos comunidades) y edad (2-4, >4-6, >6), empleando la fórmula de Pérez (2000). El número de muestras se determinó mediante la fórmula de proporciones en poblaciones finitas (Daniel, 1996), usando la prevalencia de $10.2 \%$ reportada por Saravia et al. (2004) en llamas de una empresa ganadera de Puno. 
Cuadro 1. Seroprevalencia de $T$. gondii en llamas hembras en edad reproductiva en dos comunidades de la provincia de Melgar, Puno, según lugar de procedencia y grupo etario (2003)

\begin{tabular}{llccc}
\hline \multirow{2}{*}{ Variable } & & \begin{tabular}{c} 
Animales \\
muestreados \\
\cline { 5 - 5 }$\left(\mathrm{N}^{\mathrm{o}}\right)$
\end{tabular} & \multicolumn{2}{c}{ Animales seropositivos } \\
\hline Procedencia & & & $\mathrm{N}^{\mathrm{o}}$ & $\% \pm \mathrm{I} . \mathrm{C} .^{1}$ \\
& & 30 & 11 & $36.7 \pm 17.2^{\mathrm{a}}$ \\
& Huaycho & 77 & 5 & $6.5 \pm 5.5^{\mathrm{b}}$ \\
Huataywasi & & & \\
$\begin{array}{l}\text { Grupo etario } \\
\text { (años }\end{array}$ & & & & \\
& $2-4$ & 36 & 4 & $11.1 \pm 10.3^{\mathrm{a}}$ \\
& $>4-6$ & 30 & 5 & $16.7 \pm 13.3^{\mathrm{a}}$ \\
& $>6$ & 41 & 7 & $17.7 \pm 11.7^{\mathrm{a}}$ \\
\hline
\end{tabular}

${ }^{1}$ Intervalo de confianza del $95 \%$

${ }^{a, b}$ Superíndices diferentes dentro de cada variable indican diferencias estadísticas $(p<0.05)$

Se colectó muestras de sangre por punción directa de la vena yugular. Los sueros resultantes se guardaron en congehción a $-20{ }^{\circ} \mathrm{C}$ hasta su análisis en el Laboratorio de Parasitología de la Facultad de Medicina Veterinaria de la Universidad Nacional Mayor de San Marcos, Lima.

Se detectó la presencia de anticuerpos contra $T$. gondii mediante la técnica de Inmunofluorescencia Indirecta (IFI), dada su elevada sensibilidad (98\%) y especificidad (99\%), usando 1/200 como punto de corte. Esta técnica no tiene reacciones cruzadas con otros protozoos del Phylum Apicomplexa (Packham et al., 1998). Se consideró como resultado positivo la fluorescencia total del taquizoíto, y como resultado negativo la fluorescencia apical o ausencia de fluorescencia. Los resultados se expresaron en prevalencias con intervalos de confianza empleando la fórmula de Thrusfield (1990) y Armitage y Berry (1997), respectivamente.

\section{Resultados y Discusión}

Las seroprevalencias a anticuerpos contra $T$. gondii fueron de 36.7 y $6.5 \%$ en Huaycho y Huataywasi, respectivamente (Cuadro 1). Los animales de la comunidad de Huaycho mostraron una mayor y significativa seroprevalencia que aquellos de Huataywasi $(\mathrm{p}<0.05)$.

El manejo de los animales juega, probablemente, un importante rol en la presentación de T. gondii. Las llamas de la comunidad de Huaycho forman parte de una Cooperativa Agraria de Producción, conformada por comuneros que se integran y realizan el manejo del ganado en forma conjunta, mientras que las llamas de la comunidad de Huataywasi son parte de un solo fundo, con un mayor control del ganado, y evitando el libre contacto de las llamas con otro tipo de ganado. Asimismo, las condiciones higiénico- 
sanitarias (manejo de los desechos de aborto, placentas y otros) en Huataywasi eran mejor realizadas que en Huaycho. Es conocido que el sistema de manejo y las prácticas de salud tienen un efecto significante en la presentación del parásito (Assoku, 1979, citado por van der Puije et al., 2000).

Por otro lado, el estrés del animal baja las defensas inmunes. Esto ocurre en las etapas de empadre, gestación, parto, lactación, y durante las faenas de desparasitación y esquila (Tizard, 1995). Posiblemente, factores como el tipo de explotación, manejo del ganado, y contacto de las llamas con otras especies, estarían causando un mayor estrés en los animales de la comunidad de Huaycho. Asimismo, la presencia de gatos domésticos en Huaycho y la ausencia de los mismos en Huataywasi es otro punto a considerar como factor causante de la diferencia de prevalencias entre estas dos comunidades.

Se conoce que el ooquiste puede permanecer infectivo en climas fríos, soportando temperaturas de hasta $-10{ }^{\circ} \mathrm{C}$ por 54 meses (Dumétre y Dardé, 2003). En el presente estudio, las diferencias en altitud entre las dos comunidades es casi nula y la temperatura no desciende tanto, de modo que los factores frío y altura no serían factores de importancia a considerar.

Se observó que la tasa de seroprevalencia aumenta conforme aumenta la edad de los animales, aunque no en forma significativa. Sin embargo, la edad es un factor importante toda vez que con el paso del tiempo los animales se encuentran expuestos a mayores reinfecciones a través del consumo de ooquistes infectivos (van der Puije et al., 2000). En estudios realizados en vicuñas y llamas tampoco se encontró diferencias estadísticas por efecto de la edad (Chang, 2005; Zuzunaga et al., 2006).

\section{Conclusiones}

Las seroprevalencias de Toxoplasma gondii en llamas hembras de las comunida- des de Huaycho y Huataywasi, provincia de Melgar, departamento de Puno fueron de 36.7 y $6.5 \%$, respectivamente $(\mathrm{p}<0.05)$, sin haber diferencias estadísticas por efecto de la edad de los animales.

\section{Literatura Citada}

1. Ameghino E, De Martini J. 1991. Mortalidad de crías en alpacas. Lima: IVITA. $128 \mathrm{p}$.

2. Armitage P, Berry G. 1997. Statistical methods in medical research. $3^{\text {d }}$ ed. United Kingdom: Blackwell Scientific Publ. 640 p.

3. Caldas P, Chávez A, Casas E. 2006. Seroprevalencia del Toxoplasma gondii en borregas de una empresa ganadera de la Sierra Central. Rev Inv Vet, Perú 17(1): 14-19.

4. Chang K. 2005. Seroprevalencia del T. gondii en llamas hembras de la SAIS Pachacutec. Tesis de Médico Veterinario. Lima: Facultad de Medicina Veterinaria, Univ Nacional Mayor de San Marcos. 65 p.

5. Daniel W. 1996. Bioestadística: Base para el análisis de las ciencias de la salud. $3^{\mathrm{a}}$ ed. México: Limusa. $878 \mathrm{p}$.

6. Dumétre A, Dardé M. 2003. How to detect Toxoplasma gondii oocyst in enviromental samples? FEMS Microbiol Rev 27: 651-661.

7. Fernández-Baca S. 1991. Avances y perspectivas del conocimiento de los camélidos sudamericanos. Santiago: FAO. 429 p.

8. Franco E, García W, Pezo D. 1998. Manual de crianza de llamas. Pub. Tec. $\mathrm{N}^{\circ}$ 33. Lima: FMV-UNMSM. 43 p.

9. Innes EA, Esteban-Redondo MI. 1997. Diagnóstico. En: Ortega L (ed). Tratado de patología y producción ovina. Cap 3. Madrid: Ed. Luzan. p 51-56.

10. Luzón M, Alonso A, Quintanilla GA. 1997. Etiología y biología. Toxoplasmosis - Neosporosis. Rev Aula Veterinaria OVIS 52: 11-31. 
11. Martín-Hernández I, García-Izquierdo $S$. 2003. Toxoplasmosis en el hombre. Bioquímica 28(3): 19-27.

12. Packham AE, Sverlow KW, Conrad PA, Loomis EF, Rowe JD, Anderson ML, Marsh AE, et al. 1998. A modified agglutination test for $N$. caninum: Development, optimization and comparison to the indirect fluorescentantibody test and Enzyme-Lynked Inmunoabsorvent Assay. Clin Diagn Lab Inmunol 5: 467-473.

13. Pérez C. 2000. Técnicas de muestreo estadístico. México DF: Ed Alfa Omega. $603 \mathrm{p}$.

14. Ramírez J, Chávez A, Casas E, Rosadio R, Falcón N. 2005. Seroprevalencia de Toxoplasma gondii en alpacas de comunidades de la provincia de Canchis, Cusco. Rev Inv Vet, Perú 16: 169-174.
15. Saravia M, Chávez A, Casas E, Falcón, Pinto W. 2004. Seroprevalencia de $T$. gondii en llamas de una empresa pecuaria en Melgar, Puno. Rev Inv Vet, Perú 15(1): 49-55.

16. Tizard I. 1995. Inmunología veterinaria. $4^{a}$ ed. México: Interamericana McGraw-Hill. 558 p.

17. Thrusfield M. 1990. Epidemiología veterinaria. España: Acribia. 339 p.

18. Van der Puije WNA, Bosompem KM, Canacoo EA, Wastling JM, Akanmori BD. 2000. The prevalence of antiToxoplasma gondii antibodies in Ghanaian sheep and goats. Acta Tropica 76: 21-26.

19. Zuzunaga M, Chávez A, Li O, Evaristo R. 2006. Toxoplasma gondii en vicuñas de la Reserva Nacional de Pampa Galeras. Rev Inv Vet, Perú 17: 173-177. 